\title{
Evaluation of the Antibacterial Activity and the Remineralizing Potentiality of Two Natural Extracts and Their Mixture (In Vitro Study)
}

\author{
Reham Saleh ${ }^{1}$, Shaymaa Nagi', Hanaa Elgamily ${ }^{1 *}$, Shahinaz Hassan¹, Hadeer El-Hashemy ${ }^{2}$, Mohamed Zaazou' \\ ${ }^{1}$ Department of Restorative and Dental Materials, Oral and Dental Research Institute, National Research Centre, Giza, Egypt; \\ ${ }^{2}$ Department of Pharmaceutical Technology, National Research Centre, Giza, Egypt
}

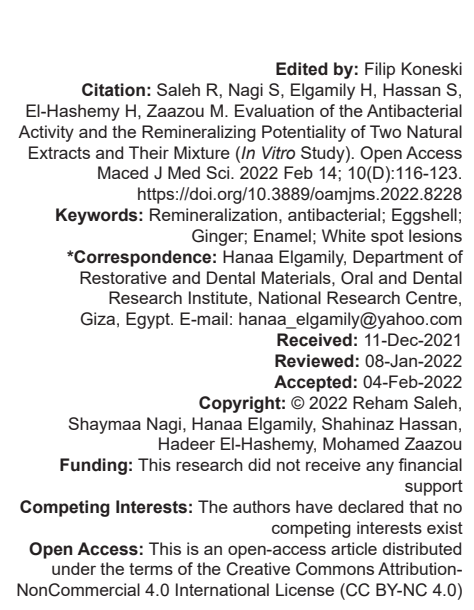

Introduction

Dental caries is considered a chronic disease throughout the whole world and still has a high prevalence in spite of having different developments in the field of dentistry focusing primarily on shifting to preventive dentistry [1]. It has been assumed that the main cause of caries is the cariogenic bacteria that cause demineralization and white spot lesions resulting in dissolution of the apatite crystals in addition to loss of the calcium and phosphate ions from the tooth surface [2].

There is a great demand to use natural products that offer antibacterial effect as well as remineralizing effect. Furthermore; using antibacterial agents have numerous negative feedback on the gastrointestinal system with elevated resistance to such chemicals. In addition, economically developing countries need costeffective and biocompatible preventive methods [3].

Among natural products, ginger rhizome (Zingiber officinale Roscoe, and Zingiberaceae) natural herbals with their antimicrobial activities as it has been stated that they have an antibacterial properties [2], [4]. In addition, there is no toxicity authorized by the United States Food and Drug Administration as 'generally recognized safe' natural planet. These herbs have a pungent oil that contain polyphenolic ketones which have a variety of pharmacological activities. Both antifungal and antimicrobial effects on oral cavity pathogens have been reported in many studies [3], [4], [5]. It has been stated that tooth paste containing ginger aids in remineralization of white spot lesions [6].

On the other hand, the outer crust of a chicken eggshell is a non-edible substance that is usually discarded. It is a porous natural substance that is been thoroughly investigated using scanning electron microscopy and microfocus X-ray scattering techniques. Chicken eggshell powder is a well-organized structure that is mainly composed of calcium carbonate (95\%). It is known as a calcium rich source with a high degree of bioavailability [7]. Furthermore, it was found that the high $\mathrm{pH}$ of the eggshell powder when used in the form of a 
solution along with its high bioavailability of the calcium content, provided it a great potentiality to enhance enamel tooth structure remineralization [8], [9]. On the other hand, it has been reported that chicken eggshell powder has an antibacterial effect [10].

Thus, it was of interest to use such natural materials to enhance remineralization as well as to modify the biofilm microbiota ecology.

\section{Methods}

\section{Preparation of the natural extracts}

\section{Preparation of ginger extract}

Ginger was obtained from a local market; it was cleaned with distilled water to remove any dirt then it was peeled into thin slices. About $100 \mathrm{~g}$ of dried rhizomes were grounded until fine particles approached. The grounded rhizomes were then soaked in three liters of ethanol (99.9\%) for $48 \mathrm{~h}$ at room temperature. Then, the supernatant was filtered through filter paper (150 mm, no.2). The supernatant was poured into rounded rotary evaporator flask using rotary evaporator (Rotavapor, WB 2000, Heidolph Instruments $\mathrm{GmbH}$ \& Co KG, Walpersdorfer, Germany). The flask was partially immersed in a water bath with $60^{\circ} \mathrm{C}$ temperature and rotating at a fixed speed of $150 \mathrm{rpm}$ for $2 \mathrm{~h}$ until the organic solvent was totally evaporated [11].

\section{Preparation of eggshell extract}

The eggshell powder was obtained by calcination in accordance with the World Intellectual Property Organization's protocol (WO/2004/105912: Method of generating eggshell powder) [12], [13]. Calcination was carried out to obtain pure powder free of pathogens and to boost the alkalinity of the powder. Twenty chicken eggs was obtained from a local market, after removal of their contents the eggshells was cleaned in distilled water then they were kept in hot water bath at $100^{\circ} \mathrm{C}$ for $10 \mathrm{~min}$ followed by removing the membrane. These eggshells were crushed using a hand blender to obtain fine powder particles. Then, the crushed shells were added into $700 \mathrm{ml}$ boiling distilled water for $10 \mathrm{~min}$. After that, eggshell powder was oven dried and re-crushed again into tiny pieces. One gram of this powder was dissolved into $20 \mathrm{ml}$ of $4 \%$ aqueous acetic acid solution [13].

\section{Preparation of mixture (eggshell/ginger extract)}

An equal volume of ginger extract and eggshell extract was mixed in a beaker under continues stirring on a magnetic stirrer for $20 \mathrm{~min}$.

\section{Characterization}

Determination of $\mathrm{pH}$ the prepared extracts

A digital $\mathrm{pH}$ meter was used to determine the $\mathrm{pH}$ of the prepared extracts (Ginger, Eggshell, and Mixture) (Jenway, Bibby Scientific Limited, Stafford-shire, UK). Before usage, the digital $\mathrm{pH}$ meter was calibrated with buffer solution at $\mathrm{pH} 7.0$ and $\mathrm{pH} 10.0$ at $25^{\circ} \mathrm{C}$.

The measurements for each sample were done in triplicates [14].

\section{Particle size analysis}

Using a Zetasizer Nano ZS (Malvern Instruments Ltd, UK), the mean size and zeta potential of the prepared extracts were measured using photon correlation spectroscopy. Before measurement, the prepared samples were adequately diluted with distilled water. For each sample, three duplicates were obtained [15].ґ

\section{assessment \\ Transmission electron microscopy (TEM)}

The prepared samples of ginger and eggshell extracts were investigated for their morphological structure using TEM «(JEOL Co., JEM-2100, Japan). On a carbon-coated copper grid, one drop of the diluted extract was applied and allowed to dry. Then, one drop of phosphor-tungstic acid solution $1 \%(\mathrm{w} / \mathrm{v})$ was mounted on the grid for $3 \mathrm{~min}$. Photomicrographs were taken for both extracts at magnification $400 \times$.

\section{extracts \\ Antibacterial assessment of the prepared}

The antimicrobial activity of the two tested extracts as well as their mixture was evaluated against both cariogenic and commensal oral bacteria using well diffusion method [15].

\section{Microorganism cultivation}

One of the oral pathogenic bacteria, Streptococcus mutans ATCC 25175, and commensal bacteria, Actinomyces viscous 1300 EMCCN, was employed to evaluate the inhibitory effects of the investigated extracts in vitro. Until cultivation for testing, the bacteria were kept on brain-heart infusion $(\mathrm{BHI})$ agar plates (Acumedia Neogen do Brasil, Indaiatuba, $\mathrm{SP}$, Brazil). Bacteria were cultured in liquid $\mathrm{BHI}$ for $12 \mathrm{~h}$ at $37^{\circ} \mathrm{C}$ with agitation at $150 \mathrm{rpm}$. Each microorganism's suspension was adjusted to $0.5 \mathrm{McF}$ arland in phosphate buffered saline [16]. 


\section{Well diffusion method}

Twenty microliters of each tested strain were impaled on the surfaces of solid mitis salivaruis agar media for $S$. mutans and nutrient tryptone soya agar for A. viscous using sterile cotton swabs. Then, wells were prepared by a cork borer in the agar layer and filled with $100 \mu \mathrm{L}$ of each tested extract and mixture of both extract. After that, plates containing $S$. mutans were cultured for $24 \mathrm{~h}$ at $37^{\circ} \mathrm{C}$ with $5 \% \mathrm{CO}_{2}$, while plates with $A$. viscous were incubated without $\mathrm{CO}_{2}$. The clear zones diameters were measured in millimeters after incubation [17], [18]. Chlorhexidine digluconate $(\mathrm{CHX})$ solution in $\mathrm{H}_{2} \mathrm{O}$ (Sigma-Aldrich, USA) and Dimethyl sulfoxide solution DMSO: 50 wt (Sigma-Aldrich, USA) were utilized as positive and negative control, respectively.

\section{Remineralization assessment}

\section{Teeth selection and preparation}

By adopting a power of $80 \%$ to detect a standardized effect size in microhardness $d=0.65$ (medium-sized standardized effect size), and the level of significance $95 \%(\alpha=0.05)$, the minimum required sample size was found to be 12 specimens per group. (Number of group $=3$ ) sample size was $12 \times 3=36$ specimens for microhardness. A total of 36 bovine anterior teeth were selected for this study. Removal of any residual tissues and debris was done by teeth scraping with hand scaler then washing under running tap water. At the level of the cementoenamel junction, the roots of the cleaned teeth were sliced with a double side cutting low speed disc. The pulpal tissues were removed with barded broaches, and the pulp chambers were sealed with pink wax [19], [20]. Except for a tiny window of $4 \mathrm{~mm} \times 4 \mathrm{~mm}$ in the middle third of the crown, the labial surface of the crowns was painted with acid resistant varnish (Nail polish, Barielle, NY, USA) to standardize the area of microhardness and Energy dispersive $\mathrm{X}$-ray (EDX) measurement.

\section{Formation of artificial carious enamel lesions}

Following baseline microhardness and EDX testing, all specimens were put through a 5 consecutive days $\mathrm{pH}$ cycling routine that included alternate demineralization for $3 \mathrm{~h}$ in a demineralizing solution, followed by remineralization for $21 \mathrm{~h}$ in artificial saliva.

At each change of medium, specimens were washed in distilled water. Every $24 \mathrm{~h}$, the demineralization solution and artificial saliva were replaced [21].

The artificial saliva had the following composition: $1.5 \mathrm{mmolL}^{-1} \mathrm{Ca}[\mathrm{NO} 3] 2.4 \mathrm{H}_{2} \mathrm{O}, 0.9 \mathrm{mmolL}^{-1}$ $\mathrm{NaH}_{2} \mathrm{PO}_{4} .2 \mathrm{H} 2 \mathrm{O}, 150 \mathrm{mmolL}^{-1} \mathrm{KCl}, 0.1 \mathrm{molL}^{-1}$ Tris buffer, and 0.03 ppm F. The saliva $\mathrm{pH}$ will be adjusted and maintained at 6.57. While the demineralizing solution had the following composition: $2.2 \mathrm{mM}$ calcium chloride $\left(\mathrm{CaCl}_{2} 2 \mathrm{H}_{2} \mathrm{O}\right)$ and $2.2 \mathrm{mM}$ monosodium phosphate (NaH2PO4 7H2O), 0.05 mM lactic acid; $\mathrm{pH}$ was adjusted to 4.5 with $50 \%$ sodium hydroxide $(\mathrm{NaOH})$. All the demineralized specimens were subjected for Vickers microhardness (VHN) and EDX testing.

\section{Study design}

The demineralized specimens were randomly assigned into three groups ( $n=12$ ) according to the used extract as follow; G1: (Ginger), G2: (Eggshell), and G3: (Mixture). Specimens of each group were separately immersed in $50 \mathrm{ml}$ of the tested extract for $12 \mathrm{~h}$ and after washing they were kept in artificial saliva for another $12 \mathrm{~h}$. This process was repeated for seven successive days using freshly prepared extracts every day. VHN test and EDX Analyzer were assessed at baseline, after demineralization and remineralization.

\section{Surface microhardness assessment}

Using rounded sectional Teflon molds of $4 \mathrm{~cm}$ diameter, with their treated labial sides facing upward, the prepared crown specimens were centered and inserted horizontally in auto-polymerized acrylic resin blocks. After setting of the acrylic resin for $1 \mathrm{~h}$, the Digital VHN tester (NEXUS 4000TM, INNOVTEST, model number 4503, The Netherlands) was used to asses enamel surface microhardness at 20x magnification while a load of $200 \mathrm{~g}$ was applied for $15 \mathrm{~s}$ [12], [22], [23], [24].

\section{EDX analysis}

Three specimens from each group were chosen randomly and evaluated using an Environmental EDX Analysis (EDX, Model Quanta 250, FEl business, Netherlands) to determine the amount of Calcium, Phosphorus, and Fluoride ions. The specimens were positioned within the chamber on aluminum stubs with the labial enamel sides facing upward. The contents of calcium, phosphorus and fluoride ions were then calculated in weight percent [25], [26], [27].

\section{Statistical analysis}

In each test, the mean and standard deviation values were computed for each group. The data were examined for normality using the Kolmogorov-Smirnov and Shapiro-Wilk tests and the data revealed a parametric (normal) distribution.

Measurement was repeated to compare more than two groups in linked samples, the ANOVA test was utilized. To compare two groups in related samples the Paired sample t-test was employed. In non-related samples, to compare more than two groups one-way ANOVA test was utilized, followed by the Tukey post hoc test. The level of significance was fixed at $p \leq 0.05$. IBM ${ }^{\circledR}$ SPSS $^{\circledR}$ Statistics Version 20 for Windows was used for statistical analysis. 


\section{Results}

\section{Results of the natural extracts characterization}

\section{$\mathrm{pH}$ results for the prepared extracts}

The $\mathrm{pH}$ results were $5.8,7.2$, and 6.2 for ginger extract, eggshell extract, and mixture, respectively.

\section{Particle size distribution and zeta potential}

The average size distribution of the prepared extracts and the mixture was found to be in the range of $5.6 \pm 4.1$ up to $11.25 \pm 6.25 \mu \mathrm{m}$. The eggshell extract showed significantly lower size distribution than that observed with either the ginger extract or the mixture extract $(p<0.05)$.

Zeta potential results were $-21.54,-18.76$, and -20.08 , for ginger extract, eggshell extract, and the prepared mixture, respectively.

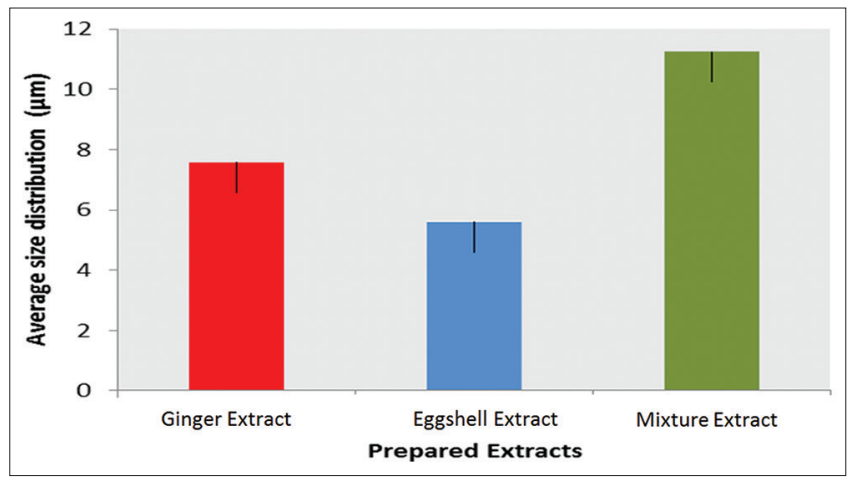

Figure 1: Size distribution or the prepared extracts

\section{TEM results}

Figure 2 showed that the structure of ginger extract showed larger size and less aggregation than eggshell extract.

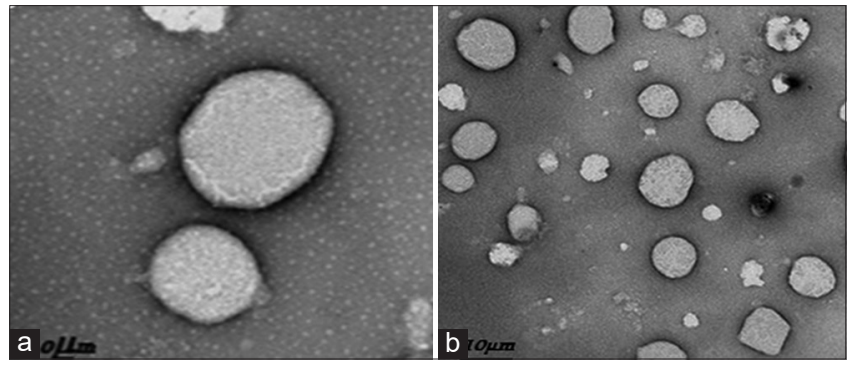

Figure 2: TEM morphological examination for (a): Ginger extract and (b) eggshell extract

\section{Antibacterial assessment}

Antibacterial assessment against S.mutans cariogenic bacteria

Mean inhibition zone diameters $(\mathrm{mm})$ for different tested extracts against $S$. mutans were presented in Table 1 and Figure 3. Results revealed that all prepared extracts had antibacterial effect against $S$. mutants.

Table 1: Mean inhibition zone diameters $(\mathrm{mm})$ for different tested extracts and the positive (CHX) and negative (DMSO) controls against Streptococoos mutans

\begin{tabular}{|c|c|c|c|c|c|}
\hline$\overline{\mathrm{CHX} \text { (+ve control) }}$ & $\begin{array}{l}\text { DMSO (-ve } \\
\text { control) }\end{array}$ & Ginger extract & Eggshell extract & Mixture & $p$-value \\
\hline $25.6(0.7)^{\mathrm{a}}$ & 0 & $18.8(0.6)^{b}$ & $17.4(1.1)^{b}$ & $26.8(0.8)^{\mathrm{a}}$ & $<0.001^{*}$ \\
\hline
\end{tabular}

There was no statistically significant difference between mixture extract and $\mathrm{CHX}$ (positive group); in terms of mean inhibition zone diameters as both had the maximum statistically significant mean inhibition zone diameters $(\mathrm{mm})$ followed by ginger and eggshell extracts

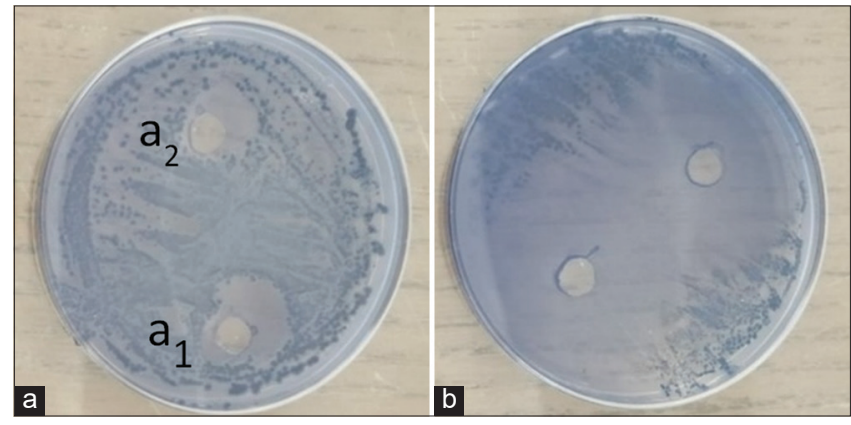

Figure 3: Antibacterial efficacy of the tested extracts against Streptococcus mutans. a: (a1; Eggshell extract, a2; Ginger extract) and (b): Mixture of extracts

where there was no statistically significant difference between them.

Antibacterial assessment against $A$. viscous commensal bacteria

Mean inhibition zone diameters $(\mathrm{mm})$ for different tested extracts against $A$. viscous are presented in table (2) and Figure 4. Results revealed that the positive control as well as ginger extract had antibacterial potential against $A$. viscous, where there was a statistically significant difference between them. While -ve control, eggshell extract, and the mixture have no antibacterial efficiency toward $A$. viscous the commensal oral bacteria.

Table 2: Mean inhibition zone diameters $(\mathrm{mm})$ for different tested extracts and the positive (CHX) and negative (DMSO) controls against Actinomyces viscous

\begin{tabular}{llllll}
\hline $\mathrm{CHX}(+\mathrm{ve}$ control) & $\begin{array}{l}\text { DMSO } \\
(- \text {-ve control) }\end{array}$ & Ginger extract & Eggshell extract & Mixture & p-value \\
\hline $32.6(1.1)^{\mathrm{a}}$ & 0 & $18.7(0.8)^{\mathrm{b}}$ & 0 & 0 & $<0.001^{*}$ \\
\hline${ }^{*}$ : Significant at $\mathrm{p} \leq 0.05$, Different superscripts are statistically significantly different &
\end{tabular}




\section{Remineralization assessment results}

\section{VHN test results}

Table (3) showed the mean, standard deviation (SD) values of the microhardness results of different groups. Results revealed that was no statistically significant difference between eggshell, ginger, and mixture groups at baseline and after demineralization, at $(p=0.490)$ and $(p=0.154)$ respectively (Figure 5$)$. On the other hand, there was a statistically significant difference between the eggshell, ginger, and mixture groups following remineralization treatment $(p<0.001)$. At $(p<0.001)$, and $(p=0.001)$, respectively,

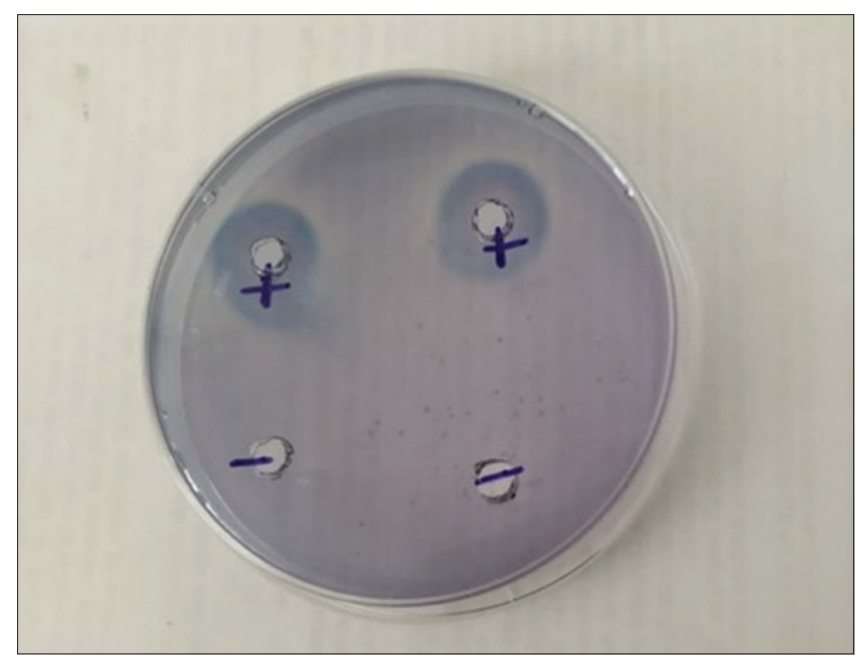

Figure 4: Antibacterial activity exhibited by positive control (CHX) and negative control (DMSO) against Streptococoos mutans

a statistically significant difference was identified between eggshell treated specimens and each of the ginger and mixture groups. In addition, there

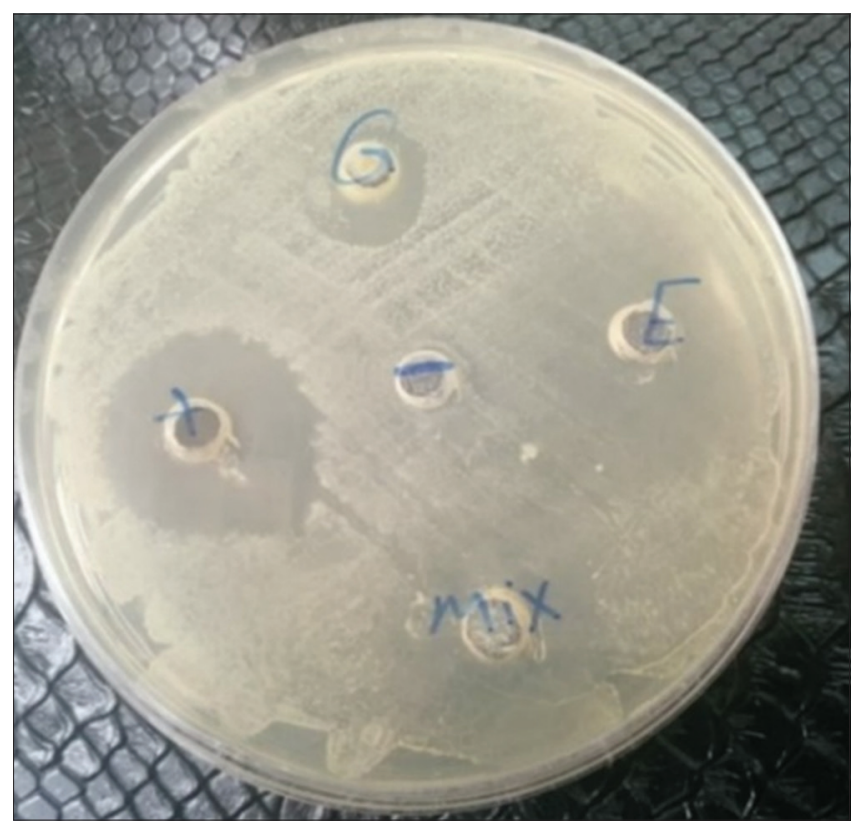

Figure 5: Antibacterial efficacy of the tested extracts against Actinomyces viscous (G; ginger, E; eggshell, +ve control, and mixture of two extracts) was a statistically significant difference between the ginger and mixture groups $(p=0.001)$. Where ginger treated specimens showed, the highest statistically significant mean microhardness, followed by mixture treated specimens. While, eggshell treated specimens showed the least statistically significant mean microhardness values.

Table 3: The mean, standard deviation (SD) values of microhardness (VHN) of different groups

\begin{tabular}{|c|c|c|c|c|c|c|c|}
\hline \multirow[t]{3}{*}{ Variables } & \multicolumn{7}{|c|}{ Microhardness (VHN) } \\
\hline & \multicolumn{2}{|l|}{ Eggshell } & \multicolumn{2}{|l|}{ Ginger } & \multicolumn{2}{|l|}{ Mixture } & \multirow[t]{2}{*}{$p$-value } \\
\hline & Mean & S.D & Mean & S.D & Mean & S.D & \\
\hline Baseline & $285.20^{\text {Aa }}$ & 8.88 & $304.15^{\text {Aa }}$ & 22.21 & $287.38^{\text {Aa }}$ & 33.14 & $0.490 \mathrm{~ns}$ \\
\hline After demineralization & $227.70^{\mathrm{Ba}}$ & 7.27 & $250.40^{\mathrm{Ba}}$ & 17.54 & $235.55^{\mathrm{Ba}}$ & 18.06 & $0.154 \mathrm{~ns}$ \\
\hline After remineralization & $152.13^{\mathrm{cc}}$ & 18.63 & $342.70^{\mathrm{Ab}}$ & 33.10 & $250.48^{\mathrm{Ca}}$ & 19.87 & $<0.001^{*}$ \\
\hline $\mathrm{p}$-value & $0.001^{*}$ & & $0.010^{*}$ & & $0.016^{*}$ & & \\
\hline
\end{tabular}

Moreover, there was a statistically significant difference between Baseline, after demineralization and after remineralization groups for each of the eggshell, ginger, and Mixture groups at $(p=0.001),(p=0.010)$, and $(p=0.016)$, respectively, when comparing each individual enamel treatment within each group. Demineralized groups showed the least statistically significant mean microhardness values. Only for ginger treated specimens, there was no statistically significant difference between baseline and after remineralization groups, at $(p=0.067)$.

Table 4: The mean, standard deviation (SD) values of Calcium (Ca) $(w t \%)$ of different groups

\begin{tabular}{|c|c|c|c|c|c|c|c|}
\hline \multirow[t]{3}{*}{ Variables } & \multicolumn{7}{|c|}{$\mathrm{Ca}(\mathrm{wt} \%)$} \\
\hline & \multicolumn{2}{|c|}{ Eggshell } & \multicolumn{2}{|l|}{ Ginger } & \multicolumn{2}{|c|}{ Mixture } & \multirow[t]{2}{*}{$p$-value } \\
\hline & Mean & S.D & Mean & S.D & Mean & S.D & \\
\hline Baseline & 64.44 & 0.45 & 64.24 & 0.48 & 64.55 & 0.99 & $0.862 \mathrm{~ns}$ \\
\hline After demineralization & 60.71 & 1.90 & 59.64 & 3.23 & 60.58 & 3.29 & $0.885 \mathrm{~ns}$ \\
\hline After remineralization & 64.51 & 1.00 & 65.67 & 0.51 & 65.25 & 0.95 & $0.309 \mathrm{~ns}$ \\
\hline $\mathrm{p}$-value & $0.110 \mathrm{n}$ & & $0.099 \mathrm{~ns}$ & & $0.128 n$ & & \\
\hline
\end{tabular}

\section{EDX analysis results}

Mean and standard deviation (SD) for $\mathrm{Ca}, \mathrm{P}$, and $\mathrm{F}(\mathrm{wt} \%)$ results for tested groups are shown in tables $(4,5$, and 6$)$. Results revealed that there was no statistically significant difference in Ca, P (wt\%) values for different groups. A statistically significant increase in $\mathrm{F}(\mathrm{wt} \%)$ after remineralization in both eggshell and ginger treated specimens as shown in tables 6 .

Table 5: The mean, standard deviation (SD) values of phosphorus (P) (wt\%) of different groups

\begin{tabular}{|c|c|c|c|c|c|c|c|}
\hline \multirow[t]{3}{*}{ Variables } & \multicolumn{7}{|c|}{$\mathrm{P}(\mathrm{wt} \%)$} \\
\hline & \multicolumn{2}{|c|}{ Eggshell } & \multicolumn{2}{|c|}{ Ginger } & \multicolumn{2}{|c|}{ Mixture } & \multirow[t]{2}{*}{ p-value } \\
\hline & Mean & S.D & Mean & S.D & Mean & S.D & \\
\hline Baseline & 28.37 & 0.82 & 28.24 & 0.21 & 28.84 & 0.68 & $0.550 \mathrm{~ns}$ \\
\hline After demineralization & 29.10 & 0.63 & 28.11 & 1.03 & 29.07 & 0.42 & $0.252 \mathrm{~ns}$ \\
\hline After remineralization & 28.09 & 0.67 & 27.79 & 0.45 & 28.21 & 0.49 & $0.641 \mathrm{~ns}$ \\
\hline $\mathrm{p}$-value & \multicolumn{2}{|c|}{$0.296 \mathrm{~ns}$} & \multicolumn{2}{|c|}{$0.634 \mathrm{~ns}$} & \multicolumn{2}{|c|}{$0.337 \mathrm{~ns}$} & \\
\hline
\end{tabular}

Table 6: The mean, standard deviation (SD) values of fluoride (F) (wt \%) of different groups

\begin{tabular}{|c|c|c|c|c|c|c|c|}
\hline \multirow[t]{3}{*}{ Variables } & \multicolumn{7}{|c|}{$\mathrm{F}(\mathrm{wt} \%)$} \\
\hline & \multicolumn{2}{|c|}{ Eggshell } & \multicolumn{2}{|l|}{ Ginger } & \multicolumn{2}{|c|}{ Mixture } & \multirow[t]{2}{*}{$p$-value } \\
\hline & Mean & S.D & Mean & S.D & Mean & S.D & \\
\hline
\end{tabular}




\begin{tabular}{|c|c|c|c|c|c|c|c|}
\hline Baseline & $1.70^{A}$ & 0.09 & $1.83^{A}$ & 0.24 & 1.72 & 0.25 & $0.706 \mathrm{~ns}$ \\
\hline After demineralization & $1.24^{\mathrm{A}}$ & 0.21 & $1.13^{\mathrm{B}}$ & 0.20 & 1.06 & 0.23 & $0.616 \mathrm{~ns}$ \\
\hline After remineralization & $2.19^{\mathrm{B}}$ & 0.08 & $2.94^{\mathrm{AB}}$ & 093 & 2.65 & 0.61 & $0.414 \mathrm{~ns}$ \\
\hline$p$-value & $0.004^{*}$ & & $0.016^{*}$ & & 0.071 & & \\
\hline
\end{tabular}

column indicate statistically significance difference

\section{Discussion}

Nowadays, the tendency toward using natural and biocompatible products has increased to avoid health problems. Hence, researchers have been trying to incorporate natural ingredients in dental product. There were plenty of studies confirmed that plants have many favorable properties such as antibacterial, antioxidant, and anti-inflammatory [3]. However, limited number of researches studied the effects of such natural extracts on cariogenic oral bacteria. Moreover, there was no research studied its effect on commensal oral bacteria. Hence, it was of value to study the antibacterial ability as well as the remineralization efficiency of naturally prepared extracts.

In this in vitro study, characterization of the prepared extract was done by measuring $\mathrm{pH}$ and particle size. The acidic $\mathrm{pH}$ of ginger extract (5.8) might favor the removal of the superficial layer on enamel surface that inhibit penetration of remineralizing particles. This was in accordance with Ambarkova et al. [22] and Liang et al. [28] and who proved that remineralization can occur even in acidic solution. On the other hand, plenty of studies stated the importance of raising the local $\mathrm{pH}$ for successful remineralization [29], [30], [31]. In accordance with such studies our research revealed that the $\mathrm{pH}$ of eggshell extract and mixture preparation were 7.2 and 6.8 , respectively. This neutral $\mathrm{pH}$ might induce fast penetration of remineralizing particles inside the demineralized tooth surface.

As shown in Figure 1, the average size distribution of the prepared extracts and their mixture were small enough to allow easy penetration of the small remineralizing particles into the demineralized enamel surface.

On the other hand, Muzzalupo et al. stated that zeta potential considered as an important indicator which reflects how much stable and free of agglomeration will be in the prepared system [31]. Our results were $-21.54,-18.76$, and -20.08 , for ginger, eggshell, and the prepared mixture, respectively. As zeta potential increases, it refers to the state of stable solution free from aggregation [32].

Regarding the antibacterial assessment test, the routinely used agar diffusion method was utilized. This method involves placing the prepared extract on an agar plate inoculated with certain oral bacteria. To produce the zone of inhibition which denote its antibacterial activity, the extract needs to leach a soluble antibacterial agent. If the amount of eluted agents was not enough the zone of inhibition will not be produced. S. mutans plays an important role in dental biofilm formation and in the etiology of caries initiation and propagation [10].

The current study proved that all of the prepared extracts had strong antibacterial effect against $S$. mutants as shown in table (1) and Figure 3. The antibacterial activity of ginger against $S$. mutants might be due to its valuable phytoconstituents which had a good binding affinity to the surface protein antigen of $S$. mutant, in addition to the hydrophobic interactions with the protein active site that increase the inhibitory effect against $S$. mutans surface protein antigen [2], [14]. On the other hand, the high concentration of bio-available calcium ions and the alkalinity of the eggshell extract were the main cause of its antibacterial activity [8], [10], [33].

To the best of our knowledge, no previous research studied the antibacterial effect of remineralizing agents against commensal oral bacteria. Philip et al. [34] stated that actinomyces were considered as anaerobic, nonvirulent commensal bacteria that were normally found in the oropharynx and gastrointestinal tract as a resident microbial flora. Actinomyces viscosus was one of the clinically relevant species. This organism required either a disruption of the natural barriers or a change in the typical microbial flora to cause infection.

According to Duggal et al., most of the microorganisms implicated in dental caries etiology were indigenous organisms and survive in a dynamic relationship with the host [35]. Disease was not always the end result of this association, but it might ensue when the balance was greatly disturbed.

Our findings revealed that only ginger extract could inhibit the commensal oral bacteria $A$. viscous. While, both eggshell extract and the mixture preparation had no antibacterial efficiency against the tested commensal oral bacteria.

Regarding VHN test results, (table 3), ginger extract, showed the highest statistically significant mean microhardness values which almost exceed the base line results, with no statistical significance. This might be due to high fluoride content of ginger [3], [36]. That was confirmed by the EDX results which showed a significant increase in $\mathrm{F} \mathrm{wt} \%$ of demineralized enamel after Ginger remineralization (table 6).

On the other hand, eggshell extract treated specimens, showed a statistically significant decrease in the mean microhardness of the enamel surface after remineralization (table 3). This was in contrary to other studies that proved that eggshell solution was capable of increasing the microhardness of demineralized enamel specimens in a statistically significant way due to its high calcium and phosphorous content that should favor the remineralization process for initial caries lesions [12], [37]. This unexpected result for the eggshell extract in the current study might be attributed to the method of extract preparation, as $4 \%$ acetic acid 
was used for its preparation, which might cause further tooth demineralization.

In the current study, the mixture of eggshell and ginger was efficient as a remineralizing solution. The efficient remineralizing role of ginger and eggshell mixture could not differentiated whether it was a result of ginger high fluoride content, or it seems that there could be certain boosting effect on initial lesions. The acidic $\mathrm{pH}$ of the eggshell solution might enhance the release of fluoride from ginger at the time of application resulting in higher remineralization when compared to the eggshell treated specimens.

Result of EDX revealed non statistical significance in $\mathrm{Ca}$ and $\mathrm{P}$ wt\% between all tested groups. Although $\mathrm{Ca}$ wt\% was increased in all groups after remineralization and exceed that of demineralization that increase was not statistically significant. That might be due that the remineralization protocol utilized in the current study was only for 7 days, in contract to other studies that found significant increase in the ions content after 15 and 30 days of remineralization [38].

\section{Conclusions}

Within limitations of this current study, it could be concluded that:

1- $\quad$ The mixture of ginger and eggshell extracts was capable of modifying the oral biofilm by having a strong antibacterial effect against S. mutans cariogenic oral bacteria and had no negative effect on $A$. viscous commensal oral bacteria.

2- $\quad$ Ginger extract as well as its mixture with eggshell had a strong remineralizing ability of the demineralized artificial enamel lesions.

\section{References}

1. Mohamed EO, SharafAA, TalaatDM, Nagui DA. Remineralization effect of eggshell powder and novamine on initial caries-like lesions in young permanent teeth (An in vitro study). Alexandria Dent J. 2020;45:52-9.

2. Abdel Tawab HA, Niazy MA, El Sharkakawy DA. Antibacterial effect of ginger, green tea and pomegranate versus chlorhexidine using stevia and sucrose sugar. Al-Azhar Dent J. 2020;7(1):329-36. http://doi.org/10.21608/adjg.2020.7838.1105

3. Gocmen GB, Yanikoglu F, Tagtekin D, Stookey GY, Schemehom BR, Hayran O. Education effectiveness of some herbals on initial enamel caries lesion. Asian Pac J Trop Biomed 2016;6:846-50

4. Bilgin G, Yanıkoğlu F, Tagtekin D. Remineralization potential of herbal mixtures: An in situ study. Paripex Indian J Res. 2016;5(2):264-8.
5. Anushri M, Yashoda R, Manjunath P. Herbs: A good alternatives to current treatments for oral health problems. Int J Adv Health Sci. 2015;1(12):26-32.

6. Kiristiogglu ZB, Yanikoglu F, Alkan E, Tagtekin D, Gocmen GB, Ilgin C. The effect of dental paste with herbal content on remineralization and the imaging with fluorescent technique in teeth with white spot lesion. Clin Exp Health Sci. 2021;11:348-53.

7. Taher HM, Bayoumi R. Remineralization of initial enamel like lesions with chicken eggshell powder solution versus amorphous calcium phosphate. Egypt Dent J. 2018;64:3703-12.

8. Feroz S, Moeen F, Haq SN: Protective effect of two different remineralizing agents on artificially induced dental erosion in primary and permanent teeth: An in vitro analysis. Pak Oral Dent J. 2017;37(4):657-66.

9. Elshik AE, Etman WM, Genaid TM. Resistance of chicken eggshell powder treated with demineralized enamel to further acidic challenges. Tanta Dent J. 2020;17:38-44.

10. Alkhalidi EF, Alsalman TH, Taqa AA. Antibacterial properties of new calcium based cement prepared from egg shell. Edorium $\mathrm{J}$ Dent. 2015;2:21-7.

11. Park M, Bae J, Lee D. Antibacterial activity of [10] gingerol and [12]-gingerol isolated from ginger rhizome against periodontal bacteria. Phytother Res J. 2008;22:1446-9.

12. Mony B, Ebenezar AV, Ghani MF, Narayanan A, Anands S, Mohan AG. Effect of chicken egg shell powder solution on early enamel carious lesions: An in vitro preliminary study. J Clin Diagn Res. 2015;9(3):ZC30-2. http://doi.org/10.7860/ JCDR/2015/11404.5656 PMid:25954701

13. Feroz S, Moeen F, Haq SN. Protective effect of chicken egg shell powder solution (CESP) on artificially induced dental erosion: An in vitro atomic force microscope study. Int J Dent Sci Res. 2017;5(3):49-55.

14. Nada M. Mostafa: Antibacterial activity of ginger (Zingiber officinale) leaves essential oil nanoemulsion against the cariogenic Streptococcus mutans. J Appl Pharm Sci. 2018;8(9):34-41. http://doi.org/10.7324/JAPS.2018.8906

15. El-Sayed SM, El-Sayed HS. Antimicrobial nanoemulsion formulation based on thyme (Thymus vulgaris) essential oil for UF labneh preservation. J Mater Res Technol. 2021;10:1029-41.

16. Espinosa L, Ruiz N, Tarín DC, López SY, Contreras AZ, Cortéz DC, et al. Antiadherence and antimicrobial properties of silver nanoparticles against Streptococcus mutans on brackets and wires used for orthodontic treatments. J Nanomater. 2018;2018:9248527

17. Beatriz BS, Marília FP, Márcio GH, Ricardo SC, Felipe AJ, Ricardo DG, et al. In vitro evaluation of the remineralizing potential and antimicrobial activity of a cariostatic agent with silver nanoparticles. Braz Dent J. 2017;28(6):738-43.

18. Elgamily $\mathrm{H}$, Ghallab $\mathrm{O}$, El-Sayed $\mathrm{H}$, Nasr M. Antibacteria potency and fluoride release of a glass ionomer restorative material containing different concentrations of natural and chemical products: An in-vitro comparative study. J Clin Exp Dent 2018;10:e312-20.

19. Zaheer AS, Tanikonda R, Girija S, Madhu V, Kalyan S, Vijayalakshmi BR, et al. Quantitative analysis of remineralization of artificial carious lesions with commercially available newer remineralizing agents using SEM-EDX-in vitro study. J Clin Diagn Res. 2017;11(4):20-3

20. Ali N, Shabnam A, Azad R, Elmira N. Impact of Nano hydroxyapatite, Nano silver fluoride and sodium fluoride varnish on primary teeth enamel remineralization: An in vitro study. J Clin Diagn Res. 2017;11(9):97-100.

21. Rao R, Jain A, Verma M, Langade D, Patil A. Comparative evaluation of remineralizing potential of fluoride using three different remineralizing protocols: An in vitro study. 
J Conserv Dent. 2017;20(6):463-6. http://doi.org/10.4103/JCD. JCD_203_17

PMid:29430102

22. Ambarkova V, Gorseta K, Glavina D, Skrinjaric I. The effect of fluoridated dentifrice formulations on enamel remineralisation and microhardness after in vitro demineralization. Acta Stomatol Croat. 2011;45(3):159-65.

23. Ambarkova V, Gorseta K, Jankulovska M, Glavina D, Skrinjaric I. Effect of the fluoride gels and varnishes comparing to CPP-ACP complex on human enamel demineralization/remineralization. Acta Stomatol Croat. 2013;47(2):99-110.

24. Mony S, Rao A, Shenoy R, Supraabha BS. Comparative evaluation of the remineralizing efficacy of calcium sodium phosphosilicate agent and fluoride based on quantitative and qualitative analysis. J Indian Soc Pedod Prev Dent. 2015;33(4):291-5. http://doi.org/10.4103/0970-4388.165667 PMid:26381630

25. Haleh H, Maryam HG, Yasaman M, Mohamad JK. The effect of two remineralizing agents and natural saliva on bleached enamel hardness. Dent Res J (Isfahan). 2016;13(1):52-7. http:// doi.org/10.4103/1735-3327.174713

PMid:26962316

26. Chris SI, Timothy LH, Frankling GG. Microhardness recovery of demineralized enamel after treatment with fluoride gel or CPP-ACP paste applied topically or with dielectrophoresis. Am J Dent. 2012;25(2):109-13.

PMid:22779285

27. Chaudhary I, Tripathi AM, Yadav G, Sonali S. Effect of casein phosphopeptide amorphous calcium phosphate and calcium sodium phosphosilicate on artificial carious lesions: An in vitro study. Int J Clin Pediatr Dent. 2017;10(3):261-6. http://doi. org/10.5005/jp-journals-10005-1447

PMid:29104386

28. Liang K, Wang S, Tao1 S, Xiao S, Zhou H, Wang P, et al. Dental remineralization via poly (amido amine) and restorative materials containing calcium phosphate nanoparticles. International Journal of Oral Science, 2019, 11-15.

29. Zhang H, Yang J, Liang K, Li J, He L, Yang AX, et al. Effective dentin restorative material based on phosphate-eterminated dendrimer as artificial protein. Colloids Surf B Biointerfaces.
2015;128:304-14. http://doi.org/10.1016/j.colsurfb.2015.01.058 PMid:25703791

30. Liang K, Yuan H, Li J, Yang J, Zahu X, He L, et al. Remineralization of demineralized dentin induced by amineterminated PAMAM dendrimer. Macromol Mater Eng. 2015;300(1):107-17. http:// doi.org/10.1002/mame.201400207

31. GaoY, Li K, Li J, Yuan H, Liu H, Duan Z, et al. Effect and stability of poly (amido amine) induced biomineralization on dentinal tubule occlusion. Materials (Basel). 2017;10(4):384-99. http:// doi.org/10.3390/ma10040384

PMid:28772744

32. Muzzalupo R., Tavano L, Cassano R, Trombino S, Ferrarelli T, Picci N. Anew approach for the evaluation of niosomes as effective transdermal drug delivery systems. Eur J Pharm Biopharm. 2011;79(1):28-35. http://doi.org/10.1016/j.ejpb.2011.01.020 PMid:21303691

33. Philip N, Suneja B, Walsh LJ. Ecological approaches to dental caries prevention: Paradigm shift or shibboleth? Caries Res J. 2018;52(1-2):153-65. http://doi.org/10.1159/000484985 PMid:29320767

34. Duggal MS, Curson ME. Dental disease: Etiology of denta caries. In: Encyclopedia of Food Sciences and Nutrition; 2003. p. 1746-9.

35. Abdo RY, Niazy MA, Gad NA. The remineralizaing potential of some natural materials alone or combined with zamzam water on demineralized enamel. Al Azhar Dent J. 2021;8(1):27-33.

36. Haghoo R, Mehran M, Ahmadvand M, Ahmadvand MJ. Remineralization effect of eggshell versus Nano-hydroxyapatite on caries-like lesions in permanent teeth (in vitro). J Int Oral Health. 2016;8(4):435-9.

37. Onwubu SC, Mduli PS, Singh S, Bharuth V. An in vitro examination on the effectiveness of commercial toothpastes in the prevention of tooth decay, using eggshell as a substitute for human tooth material. South Afr Dent J. 2018;73(7):446-51.

38. Klaric E, Rakic M, Sever I, Milat O, Par M, Tarle Z. Enamel and dentin microhardness and chemical composition after experimental light-activated bleaching. J Oper Dent. 2015;40(4):E132-41. http://doi.org/10.2341/14-148-L

PMid:25748206 